\title{
May the passion be with you: The addictive potential of collectible card games, miniatures, and dice of the Star Wars universe
}

\author{
FRAN CALVO $^{1,2 *}$, XAVIER CARBONELL ${ }^{2}$, URSULA OBERST $^{2}$ and HÉCTOR FUSTER ${ }^{3}$
}

${ }^{1}$ Department of Pedagogy, FPE, University of Girona, Girona, Spain

${ }^{2}$ Department of Psychology, FPCEE, Ramon Llull University, Barcelona, Spain

${ }^{3}$ School for Interactive New Technologies (Escola de Noves Tecnologies Interactives, ENTI), Barcelona, Spain

(Received: March 20, 2018; revised manuscript received: May 12, 2018; second revised manuscript received: June 16, 2018; accepted: June 19, 2018)

\begin{abstract}
Background and aims: In recent years, we have witnessed a growing research interest in behavioral addictions and in pleasurable behaviors that generate a certain discomfort in the people who engage in them. The objective of this study was to assess if users of collectible card games, miniatures, and dice from the Star Wars Universe Games (SWUG) may also present criteria of addiction and if the presence of these criteria is related to demographic variables, game-playing habits, and other variables. Methods: SWUG players were contacted through specialized gaming chats, and 218 of them completed the Internet Gaming Disorder Scale - Short Form (IGDS-SF9), a scale that assesses motivation to engage in the game (Massively Multiplayer Online Motivations Scale), the Rosenberg Self-Esteem Questionnaire, the Diener Satisfaction with Life Scale, and a question for the self-assessment of addiction. Results: Significant predictors of addictive symptoms were the motivation to seek dissociation and (negatively) self-esteem. Users more significantly dedicate indirect hours to the game (thinking about the game, preparing material, etc.) than to actually playing. No participant could be considered pathologically addicted, as no one scored above the tentative cut-off point of the IGDS-SF9. Discussion and conclusions: Despite the fact that many players considered themselves "addicted" and some presented various economic and family problems related to their activity, it was found that playing these games could not be equated to true addictive behavior, since no player had scores above the cut-off point. This finding contributes to current discussions about the tendency to overestimate excessive pleasurable behaviors.
\end{abstract}

Keywords: behavioral addictions, analogical games, self-esteem, motivations to game-playing, Internet gaming disorder, gaming

\section{INTRODUCTION}

\section{Gaming in the context of behavioral addictions}

In recent years, we have witnessed a growing interest in behavioral addictions. The fifth edition of the Diagnostic and Statistical Manual of Mental Disorders (DSM-5; American Psychiatric Association [APA], 2013) has first listed a substance-free addiction - pathological gambling - as an addiction. The DSM-5 stops short of classifying another widely discussed disorder as addiction, that is, Internet gaming disorder (IGD). However, it lists IGD under the section of disorders that warrant more research and clinical studies for possible consideration as a mental disorder. IGD is characterized by the persistent and recurrent use of the Internet to participate in video games, often with other players. Surprisingly, the DSM-5 does not consider other possible addictions such as shopping or sex addiction; these are qualified as "repetitive behaviors," but they lack, in its opinion, sufficient data to establish the diagnostic criteria and a description of course. Therefore, we are in a decisive moment for understanding and describing behavioral addictions.
Scholars have debated whether the DSM-5 will help or hinder the diagnosis and conceptualization of IGD (Carbonell, 2014; Kuss, Griffiths, \& Pontes, 2016) and also discussed the difficulty in reaching consensus on the new, diverse, and constantly evolving phenomenon of online video games (Carbonell, 2017). In spite of this situation, the psychological research on IGD shows that some underlying cognitions meet the criteria of problematic gaming and can help understand this phenomenon. One of these cognitions is the overreliance on gaming to meet self-esteem needs (King \& Delfabbro, 2014).

Somewhat contradictorily, the DSM-5 (APA, 2013, p. 796) points out that IGD "involves specific Internet games but [...] could involve non-Internet computerized games as well." This definition opens the door to other (offline) video games and, from an even broader perspective, to analogical

\footnotetext{
* Corresponding author: Fran Calvo; Department of Pedagogy, FPE, University of Girona, Pujada de Sant Domènec, 9, Girona 17004, Spain; Phone/Fax: +34 9724183 00; E-mail: fran.calvo@ udg.edu
}

This is an open-access article distributed under the terms of the Creative Commons Attribution-NonCommercial 4.0 International License, which permits unrestricted use, distribution, and reproduction in any medium for non-commercial purposes, provided the original author and source are credited, a link to the CC License is provided, and changes - if any - are indicated. 
games ("analogical" understood as opposed to virtual or online). Although very different from online role-playing games, some traditional games feature vast universes that increase the player's participation possibilities. The market for board games has grown steadily in recent years and this trend is expected to remain stable (Martin, 2017). These games, consisting of collectible cards, miniatures, and/or dice, generally recreate fictional universes, such as medieval fantasy sagas or science fiction scenarios. They come from the popularization of classic role-playing games, which originated in 1974 with Dungeons and Dragons (Schick, 1991). Almost 20 years later, Magic: The Gathering was born. In this game, players construct decks of collectible cards, which are periodically published in expansion packs including new updates of playing cards and game rules. Acquiring the updates makes a player more successful in competing with other players (Bosch, 2000). With the success of sagas based in film, television, novels, or comic books, such as Game of Thrones, Lord of the Rings, and The Living Dead, there has been an increase in the availability of this type of games. Some of the most successful in the market have been the various Star Wars Universe Games (SWUG), such as X-Wing, Star Wars Armada, Imperial Assault, Star Wars Destiny, and Star Wars Card Game. The first three are miniatures and cards; in addition, in Imperial Assault, the player can customize the miniatures with paint. Star Wars Destiny is a game of cards and dice, and Star Wars Card Game is exclusively a card game.

One of the most popular games is $X$-Wing. In this game, players control miniature starfighter ships from the Rebel Alliance, the Galactic Empire, or Mercenaries (also called Scum or Villainy). The ships, which are replicas from the different movies, series, and comic books of the saga, are handcrafted and of high quality. Each ship can be equipped with different pilots, represented in cards that include different skills for each of them. The ships can also be modified with improvement cards, which make them more competitive in the game. These ships and pilots can be combined with pieces contained in the expansion packs that appear on the market several times a year. The continuing expansion of the game makes it possible for players to personalize their vehicles and characters almost infinitely. Another attractive feature of the game is that it can be learned in a few minutes. It is played with cards, maneuver dials and templates, range rulers, laser levels, and dice. The players' ships fight against each other in battles with different levels of complexity, depending on the game mode. However, the most popular mode takes $11 / 2 \mathrm{hr}$ and is played on boards of $90 \mathrm{~cm}^{2}$.

\section{Self-esteem and satisfaction with life}

In the psychology of the life cycle, game playing has been associated with positive effects, such as socializing, learning rules, increased tolerance for frustration, achievement and improvement of physical and/or cognitive skills, such as memory, attention, etc. (for a review, see Bjorklund \& Pellegrini, 2010). SWUG is an analogical game for adults and teenagers that is very clearly distinguished from gambling and video gaming, but which could have negative consequences on the psychological well-being of the habitual player. For instance, some players could present the criteria used to diagnose gambling disorder and IGD (APA, 2013). These games require a significant economic investment to be able to acquire the continuous updates developed by the market, in order to increase one's competitiveness in tournaments. They also require time to prepare game strategies, paint the miniatures, build the decks of cards, prepare lists of components used in each tournament, and carry out other tasks, according to the game in question. This need to adapt to context pressure could be a generating discomfort in the players and their families.

Among the symptoms related to excessive game-playing, negative emotions concerning self-esteem and satisfaction with life stand out. Self-esteem can be defined as the set of perceptions, thoughts, and evaluations about oneself; it is the evaluative perception of oneself (Rosenberg, 1965). Self-esteem figures in Maslow's (1954) hierarchy of needs, and human beings have a vital need to maintain and/or increase it. It has been observed that people with low selfesteem seek compensatory means to increase it. This has been found in the case of drug users (Khantzian, 1985), problematic Internet users (Niemz, Griffiths, \& Banyard, 2005; Widyanto \& Griffiths, 2011), problematic mobile users (Leung, 2007), and people who perpetrate intimate partner violence (Loinaz, Echeburúa, \& Ullate, 2012). Self-esteem is one of the constructs included in the set of affective components, related to mood and emotions that make up the concept of psychological well-being, together with cognitive judgments about satisfaction with life (Crocker, Luhtanen, Blaine, \& Broadnax, 1994).

Satisfaction with life is defined as the overall evaluation that people make in their lives. When evaluating his or her satisfaction with life, the individual examines the tangible aspects of life, weighs the good against the bad, compares them with his or her expectations, and comes to a judgment about his or her satisfaction (Atienza, Pons, Balaguer, \& García-Merita, 2000; Cabañero et al., 2004). Lower selfesteem and less life satisfaction have been related, among other things, to drug use (Greger, Myhre, Klöckner, \& Jozefiak, 2017; Manganiello, 1978), and the excessive use of the Internet (Widyanto \& Griffiths, 2011) and online video games (Caplan, Williams, \& Yee, 2009; KardefeltWinther, 2014).

\section{Motivations for gaming}

Another line of research in the field of video games is the study of players' motivations. Among the most studied motives are socializing (making friends via the game and interacting with them), exploration (discovering the various facets and possibilities of the game), achievement (being a leader, having prestige among other players), and escape from real life or dissociation (avoiding negative feelings associated with aspects of real life; Fuster, Carbonell, Chamarro, \& Oberst, 2013; Fuster et al., 2012; Kahn et al., 2015; Yee, 2006). Achievement and escapism were central motivations in problematic video gaming. Previous research has theorized that problematic video gaming may often lead to uncontrolled achievement seeking in the game or a maladaptive coping strategy for dealing with negative 
emotions (Billieux et al., 2013). Schimmenti, Guglielmucci, Barbasio, and Granieri (2012) demonstrate that many of their participants with problematic Internet use also showed a higher degree of dissociation, and that dissociation mediated the effect of attachment disorganization on Internet addiction. Drawing on contemporary psychoanalytical theory, the authors put forward that painful states of mind related to attachment trauma are defensively excluded from awareness through dissociation and absorption into virtual worlds (Schimmenti \& Caretti, 2010). Simultaneously, one of the most important motivations for game-playing is social: players make friends through the game and these can transcend the virtual context to become significant realworld friendships (Fuster et al., 2013). The game is also a space for experimentation, belonging to a group, social support, and having fun together (Yee, 2006). However, it must be noticeable that there is a component of escapism in any form of leisure activity and that people develop hobbies as an alternative to their obligation, as forms of selfrealization. Hence, understanding players' motivations for playing is important in predicting its long-term consequences.

\section{The present study}

Given the need to progress in the conceptualization and diagnosis of behavioral addictions, the objectives and hypotheses of this research are: (a) to describe SWUG players in terms of demographic characteristics and gameplaying habits; it is expected that, as for other types of players and gamers, the self-selected sample will mainly consist of young men (H1); (b) to evaluate if they possess symptoms that are compatible with the diagnosis of a behavioral addiction, similar to those that can be observed in video gamers. In general, we expect little symptomatology (H2); and (c) to determine the relationship of addictive symptoms with self-esteem, life satisfaction, and motivation to play; lower scores in satisfaction with life and in self-esteem, as well as higher scores in motivation to seek dissociation are expected to predict more severe symptoms of addiction (H3).

\section{METHODS}

\section{Participants and procedure}

Different chats and forums of players were located through physical or virtual stores and chats or web pages specialized in SWUG. We contacted the administrators of 11 of these forums (mostly groups conducted through the instant messaging application like WhatsApp), with a total of 722 registered players (some players belong to more than one forum). They were informed of the characteristics of the study; their informed consent was requested and they were invited to participate in a raffle for a $€ 30$ voucher from a well-known online game store to thank them for their participation.

A total of 233 players of one or more SWUG responded in May 2017 to an online questionnaire, which they reached by clicking a link that was published on the aforementioned forums.

\section{Measures}

Sociodemographic data and playing habits. Basic demographic information was assessed (gender, age, and relationship status). Basic playing habits and type of game were assessed through and ad hoc questionnaire: hours dedicated to game-playing, hours dedicated to the game before a tournament (thinking about the game, creating strategies, preparing card desks or lists, reading articles, etc.), preferred SWUG game, types of SWUG played and with what frequency, faction used (Empire, Rebels, or Scum), and participation or not in tournaments. In addition, participants were asked through a single item if they considered themselves to be addicted to this type of games, on a Likert scale from 1 (totally agree) to 5 (totally disagree), and if they had ever considered seeking medical or psychological help for this problem.

Addiction to SWUG. An adapted version of the "Internet Gaming Disorder Scale - Short Form 9" (IGDS-SF9; Pontes \& Griffiths, 2015) was used. The IGDS-SF9 is a short scale that evaluates IGD according to the DSM-5 in nine items, corresponding to the nine DSM-5 criteria of IGD, for example, "Do you feel the need to spend more and more time playing to achieve satisfaction or pleasure?" The answers are given on a Likert scale ranging from 1 (never) to 5 (very often); therefore, the minimum possible score is 9 and the maximum possible score is 45 . According to the authors of the IGDS-SF9 (Pontes \& Griffiths, 2015), the objective of this instrument is not to diagnose a possible disorder but to assess its severity and the negative effects for the player's life; however, they state that for research purposes, players scoring at least 36 out of 45 possible points can be classified as pathological. But as the DSM-5 diagnostic criteria for IGD require the presence of at least five (out of nine) symptoms, for the purpose of this study, we used a more conservative approach by assuming that endorsing "often" or "very often" to more than four items that would be indicative of addiction. The original English version was translated into Spanish using the step-by-step process described by Sperber (2004): (a) translation into Spanish by two native English speakers with Spanish fluency, (b) comparison of the two versions and construction of an initial version in Spanish, (c) back translation into English by another independent translator, and (d) comparison of the two English versions and translation into Spanish, once possible discrepancies were resolved. The resulting version was piloted with three players who indicated no comprehension problems. The reliability for this scale in this study (Cronbach's $\alpha$ ) was .803 .

Self-esteem. To assess self-esteem, the Rosenberg SelfEsteem Scale (Rosenberg, 1965) was applied in the version, adapted and validated for the Spanish population by MartínAlbo, Núñez, Navarro, and Grijalvo (2007). It measures global self-esteem based on the perception of positive and negative feelings toward oneself on a scale of 10 Likert-type items with four response options ranging from 1 (strongly disagree) to 4 (strongly agree), for example, "I have a positive attitude toward myself." The reliability for this scale in this study was $\alpha=.831$.

Satisfaction with life. The Life Satisfaction Scale was used (Diener, Emmons, Larsen, \& Griffin, 1985), adapted 
and validated for the Spanish population by Atienza et al. (2000). It evaluates the cognitive perception of subjective well-being based on the global assessment that each person makes about his or her own life through five items and five response options from 1 (strongly disagree) to 5 (strongly agree), for example, "The circumstances of my life are very good." The reliability for this scale in this study was $\alpha=.903$.

Motivation for the game. The Massively Multiplayer Online Motivations Scale (MMO-MS; Fuster et al., 2012) was used and adapted to SWUG in order to evaluate the motivations to game-playing. The scale consists of 20 items divided into four scales, such as socializing (three items), exploration (five items), achievement (five items), and dissociation (seven items). The item of the exploration scale "I like that the game has no end," which is a feature exclusive of MMO-MS, was changed into "I like to explore the Star Wars universe that is recreated in the game." Participants were asked to indicate their level of agreement with each item on a 7-point Likert scale ranging from 1 (strongly disagree) to 7 (completely agree). The reliability for this instrument in this study was $\alpha=.703$ for socializing, .790 for exploration, .840 for achievement, and .779 for dissociation.

\section{Statistical analysis}

The frequencies of the demographic variables and game habits were calculated, as well as the degree of self-rated addiction. We calculated the descriptive statistics (means and standard deviations) of the hours dedicated to the game, the scores on the questionnaires, as well as the intercorrelations using the Pearson's coefficient. Descriptive statistics and intercorrelations were also calculated for the self-evaluation of addiction and the individual items of the IGD9-SF, using the Spearman's coefficient. To assess whether the preferred game or faction was associated with greater or lesser addiction, contingency tables were calculated between preferred game and selfevaluated addiction, and between faction and selfevaluated addiction. An analysis of variance between continuous variables and preferred game/faction was run to determine whether there was a difference between game preferences. Finally, a linear regression model was adapted to the data.

\section{Ethics}

The study procedures were carried out in accordance with the Declaration of Helsinki. The institutional review board of the Institut d'Assistència Sanitària, CEi Girona approved the study. All subjects were informed about the study and all provided informed consent.

\section{RESULTS}

\section{Gaming habits}

After eliminating the three participants who left before completing the questionnaires and the outliers by means of the Mahalanobis distance analysis (Tabachnick \& Fidell, 2007), 218 valid responses were obtained. Of these remaining participants, 211 were men $(96.8 \%)$ and 7 were women $(3.2 \%)$. For further analysis, men and women were taken together. The age range was from 14 to 53 years with an average of 34.96 years $(S D=6.73)$. Regarding their relationship status, $132(62.6 \%)$ lived with a partner, $49(23.2 \%)$ lived with their family of origin, $24(11.4 \%)$ lived alone, and $6(2.8 \%)$ reported a different situation. The games used by our participants were as follows. $X$-Wing: 190 participants (82.2\% of our sample), Destiny: 69 (31.7\%), Armada: 28 (12.8\%), Imperial Assault: 91 (41.7\%), and Living Card Game: 34 (15.6\%); the accumulated percentage exceeds $100 \%$, because several people play more than one game. The game preferred by the vast majority of participants was $X$-Wing (63.3\%), followed by Imperial Assault (17.9\%), Destiny (9.2\%), Armada (5.0\%), and Living Card Game $(4.6 \%)$.

The users spent an average of $3.68 \mathrm{hr}$ per week $(S D=$ 2.47 ) playing the games and an average of $5.77 \mathrm{hr}$ preparing tournaments $(S D=6.38)$. Rebels and Empire were the most popular factions (both preferred by $37.2 \%$ of players), while Scum and Villainy were preferred by another $25.7 \%$ of the players. About $80.3 \%$ of the players participated in tournaments, with an average of 9.82 tournaments during the year prior to the survey $(S D=16.44)$. The players who participated in tournaments spent more hours playing the games $[t(216)=-3.154, p=.002]$ and preparing tournaments $[t(216)=-3.57, p<.001]$, and they sought more socializing $[t(216)=-3.05, p=.003]$.

\section{Addiction to Star Wars games and its correlates}

The means and standard deviations of the scores obtained for the scales and intercorrelations are shown in Table 1.

The majority of users considered themselves "addicted" to this type of game: about $23.9 \%$ were "very much in agreement" that he or she considered himself or herself as an addict, 33.5\% answered "in agreement," 25.2\% neither agreed nor disagreed, $15.6 \%$ disagreed, and $1.8 \%$ (four users) totally disagreed. No one had sought professional help for addiction. However, as shown in Table 2, the self-assessment correlated with the total IGD-SF9 score and each of its items; this indicates that their selfperception of addiction coincides with what the IGDS-SF9 assesses. Self-assessment also correlated with dissociation $(\mathrm{Q}=0.289, p<.001)$, but not with the other motivations or with self-esteem and life satisfaction. No participant scored above the cut-off point of 36 proposed by Pontes and Griffiths (2015), and only one had replied "often" or "very often" to more than four items. The means and standard deviations of the scores obtained in the scales and intercorrelations are shown in Table 2.

The contingency tables did not show any association between preferred game and self-assessed addiction nor between faction and self-evaluated addiction. The analysis of variance between continuous variables and preferred game/faction did not show significant results, that is, neither the game preferred by participants nor the faction they played had an influence on self-esteem, life satisfaction, motivation, or IGD score. As can be observed in Table 1, 
Table 1. Descriptive statistics of the scales (means, $S D$ s, and correlations)

\begin{tabular}{|c|c|c|c|c|c|c|c|c|c|c|c|c|}
\hline Variable & $M$ & $S D$ & Hours & Direct & Indirect & IGD & $\mathrm{SE}$ & LS & SOC & EXP & $\mathrm{ACH}$ & DIS \\
\hline Age & 34.96 & 6.37 & .011 & -.055 & .008 & .052 & .118 & .047 & .018 & $-.171^{*}$ & -.124 & -.072 \\
\hline Total hours & 9.45 & 7.64 & - & $.630 * *$ & $.954 * *$ & .025 & $.139 *$ & -.020 & .075 & $.263 * *$ & .129 & $.154 *$ \\
\hline Direct hours & 3.68 & 2.47 & & - & $.367 * *$ & .089 & .020 & -.061 & -.021 & $-.162 *$ & .008 & $.185^{* *}$ \\
\hline Indirect hours & 5.76 & 6.38 & & & - & .132 & .020 & .000 & .098 & $.253 * *$ & $.151^{*}$ & .112 \\
\hline IGD & 15.00 & 4.56 & & & & & $-.248 * *$ & $-.164 *$ & .101 & .012 & $.202 * *$ & $.503^{* *}$ \\
\hline SE & 34.28 & 4.26 & & & & & - & .609 & -.038 & .047 & .054 & $-.216^{* *}$ \\
\hline LS & 18.91 & 3.96 & & & & & & - & .008 & -.034 & .075 & -.110 \\
\hline SOC & 15.67 & 3.23 & & & & & & & - & $.354 * *$ & $.244 * *$ & .085 \\
\hline EXP & 28.69 & 4.80 & & & & & & & & - & $.376^{* *}$ & .016 \\
\hline $\mathrm{ACH}$ & 17.89 & 6.89 & & & & & & & & & - & $.331 * *$ \\
\hline DIS & 18.24 & 7.86 & & & & & & & & & & - \\
\hline
\end{tabular}

Note. IGD: Internet gaming disorder; SE: self-esteem; LS: life satisfaction; SOC: socialization; EXP: exploration; ACH: achievement; DIS: dissociation; $S D$ : standard deviation.

${ }^{*} p<.05 .{ }^{* *} p<.001$.

Table 2. Means and SDs and intercorrelations of self-reported addiction and IGDS-SF9 items

\begin{tabular}{|c|c|c|c|c|c|c|c|c|c|c|c|c|}
\hline & $M$ & $S D$ & i1 & i2 & i3 & i4 & i5 & i6 & i7 & i8 & i9 & Total IGD \\
\hline Self-report & 2.38 & 1.06 & $.379 *$ & $.361^{*}$ & $.449 *$ & $.310^{*}$ & $.303^{*}$ & $.331 *$ & $.342 *$ & $.207^{*}$ & $.260 *$ & $.511^{*}$ \\
\hline i1 & 2.12 & 0.91 & & $.478^{*}$ & $.466^{*}$ & $.334^{*}$ & $.313^{*}$ & $.248^{*}$ & $.266^{*}$ & $.280^{*}$ & .186 & $.702 *$ \\
\hline i2 & 1.67 & 0.82 & & & $.495^{*}$ & $.457^{*}$ & $.325^{*}$ & $.329 *$ & $.247^{*}$ & $.348^{*}$ & $.202 *$ & $.683^{*}$ \\
\hline i3 & 1.80 & 0.89 & & & & $.484^{*}$ & $.376^{*}$ & $.392 *$ & $.274 *$ & $.294 *$ & $.285^{*}$ & $.735^{*}$ \\
\hline i4 & 1.59 & 0.71 & & & & & $.336^{*}$ & $.446^{*}$ & $.326^{*}$ & .128 & $.272 *$ & $.615^{*}$ \\
\hline i5 & 2.12 & 0.99 & & & & & & $.279 *$ & $.244^{*}$ & $.178^{*}$ & $.254^{*}$ & $.631 *$ \\
\hline i6 & 1.47 & 0.77 & & & & & & & $.418^{*}$ & $226^{*}$ & $.417^{*}$ & $.605^{*}$ \\
\hline i7 & 1.30 & 0.66 & & & & & & & & $.311^{*}$ & $.402 *$ & $.516^{*}$ \\
\hline i8 & 1.78 & 0.94 & & & & & & & & & $.270^{*}$ & $.530^{*}$ \\
\hline i9 & 1.14 & 0.46 & & & & & & & & & & $.416^{*}$ \\
\hline IGD total score & 15.00 & 4.56 & & & & & & & & & & - \\
\hline
\end{tabular}

Note. IGDS-SF9: Internet Gaming Disorder Scale - Short Form 9; IGD: Internet gaming disorder; SD: standard deviation; i1: preoccupation with gaming behavior; i2: irritability; i3: need to spend; i4: loss of control; i5: loss of interest; i6: problems; i7: deception and lies; i8: escape or relief; i9: jeopardized relationships.

$* p<.001$.

the score in the IGDS-SF9 was negatively associated with self-esteem and satisfaction with life, and positively associated with the motivation of achievement and dissociation. Interestingly, users dedicated many more indirect hours to the game (thinking about the game, preparing material, etc.) than to actually playing $[t(217)=5.181, p<.001]$. It is noted that age was only related to the motivation of exploration, but the observed association was weak. Both hours playing and hours preparing were related to exploration and dissociation, which are the indicators that the game is used to explore the possibilities of the game itself, but also to evade negative feelings in everyday life.

We found a negative correlation between self-esteem and dissociation and a positive correlation between socializing and exploration, socializing and achievement, and achievement and dissociation. The age of the users correlated negatively, but weakly with exploration $(r=-.171$, $p<.05)$. There was no association between score on the IGDS-SF9 and age, hours of playing or preparing the game, or with the number of tournaments played. We calculated a linear regression model on IGD with the stepwise method, entering the psychological variables self-esteem, and satisfaction in the first step and the motivations that had shown a significant correlation with the IGD (achievement and dissociation) in the next step. A significant model was obtained with $F(2,215)=40.36$ and $p<.001$, which explains $27 \%$ of the variance of IGD $\left(R^{2}=.273\right)$. Significant predictors were self-esteem $(\beta=-0.146, t=7.91, p=.015)$ and dissociation $(\beta=0.471, t=7.91, p<.001)$.

\section{DISCUSSION}

This study has allowed a brief description of the table game players of the Star Wars universe and the potentially addictive features of these games. As expected, Spanish SWUG players who participate in forums and compete in tournaments are almost exclusively men are adults $(\mathrm{HI})$ and mainly live with a partner. Although these demographic characteristics are similar to those of Spanish online gamers, in these analog players, men abound more, they are older, and they are less dependent on their family of origin (Fuster, Carbonell, Pontes, \& Griffiths, 2016).

The results indicate that the players perceive themselves as more addicted than their scores in the IGDS-SF would suggest, and that their immersion in the game is mainly 
related to the motivations of achievement and dissociation. The participants in this study dedicate many hours to their hobby, especially those who participate in tournaments, and play a variety of games related to the Star Wars universe. Although $57.3 \%$ agree or strongly agree with the statement "I am addicted to games," no participant scored above the cut-off point in the IGDS-SF9 proposed by Pontes and Griffiths (2015), and using our own more restrictive approach, only one participant replied "often" or "very often" to five or more items. This confirms $H 2$ that participants cannot be considered as addicted. Therefore, despite this addictive self-perception motivating this study in the first place, SWUG has to be considered a non-addictive hobby. When this same question was raised to a group of Spanish university students about their use of the Internet ("I am addicted to the Internet"), $47.4 \%$ strongly agreed or agreed with this statement (Carbonell, Chamarro, Oberst, Rodrigo, \& Prades, 2018) and the percentage grew to $51.9 \%$ in a sample of participants from English-speaking online forums (Pontes, Szabo, \& Griffiths, 2015). Unlike these cases, the question cannot be used as a basic screening test for problematic SWUG use or SWUG addiction, as no participant presented IGDS-SF scores above the cut-off point. In addition, and as additional evidence, none of the participants had requested treatment for their "addiction" or believed that they would need it.

Thus, we are in a situation similar to the one that motivated Mihordin (2012) to criticize current trends in conceptualizing and diagnosing behavioral addictions. Mihordin's ironic take on the study of railway modeling "addiction" shows, like this study, that practitioners or players invest a great deal of time in their hobby; however, while some may perceive themselves as addicts, others may find the question offensive. Actually, three players abandoned the questionnaire before completing it and asked the researchers about the meaning of some items, because they thought that there was nothing negative in this practice and they did not understand how they could relate to some of them. Undoubtedly, many of them might meet one or more criteria of addiction (invest time and money, hide expenses, and spend less time with family and on other leisure activities). However, the experience of this symptomatology is different from that of addictions to substances or of pathological gambling. Therefore, we must distinguish heavy use from addiction, because, despite the presence of tolerance, prominence, and emotion modification in both, only addiction generates conflict, withdrawal syndrome, and relapse (Charlton \& Danforth, 2007). The items that obtained the highest average scores were loss of interest in other hobbies and preoccupation with gaming behaviors. Low- and mid-range scores emerged for loss of control and negative consequences, suggesting that these players' behavior cannot be considered a true addiction (Deleuze et al., 2015).

The average scores of the self-esteem questionnaires lay within the normal range, between 30 and 40 points, which indicate that SWUG players have normal or even heightened self-esteem (Martín-Albo et al., 2007). The average results of life satisfaction are similar to the work of Arrindell, Heesink, and Feij (1999) with young adults from the general population $($ mean $=18.7$ ) and even higher than those of
Diener et al. (1985) with the young university population (average $=16.8$ ).

As was the case with video gamers (Fuster et al., 2012; Griffiths, 2010), we did not find a correlation between hours dedicated to the game and addiction. Nor did we find that self-assessment of "addiction" can be considered an addiction criterion, quite unlike what happens with studies on addiction and problematic Internet use (Pontes et al., 2015).

The main reason for playing is the desire for exploration and socializing, as found in previous studies with video gamers (Fuster et al., 2013; Yee, 2006). We can confirm that the motivation of dissociation is the most potent predictor of IGD symptoms, together with low self-esteem and low satisfaction with life (H3), although the achievement motivation may also have a certain effect. Therefore, these two motivations can be considered the most maladaptive, while exploration and socializing can be considered adaptive or neutral. While achievement may be halfway between adaptive and maladaptive, dissociation is emerging as the most maladaptive element, since it has also shown a negative correlation with self-esteem in other studies (Carbonell, Talarn, Beranuy, Oberst, \& Graner, 2009; Fuster et al., 2012; Hagström \& Kaldo, 2013; Hussain \& Griffiths, 2009; Kaczmarek \& Drążkowski, 2014; Wood, Griffiths, \& Parke, 2007). From a clinical point of view, dissociation is a psychological process characterized by a disruption in the normal integration of consciousness, memory, subjective identity, emotion, perception, and behavior (DSM-5; APA, 2013), which serve to compartmentalize distressing feelings as a coping mechanism. If activated excessively, the dissociation process can lead to psychopathological symptoms. In psychoanalytic theory, dissociation is commonly understood as a defense mechanism through which behaviors, thoughts, memories, and feelings become split off from one another (see Schimmenti \& Caretti, 2016).

Our results suggest that people with low self-esteem may seek dissociation and escape from discomfort through games and therefore have a higher risk of developing addictive behaviors or experiencing negative effects due to their hobby. Obviously, people with low self-esteem who play to dissociate from reality are more at risk of generating addictive behavior, of having fewer coping strategies, and of suffering other psychological disorders (Khantzian, 1985; Leung, 2007; Loinaz et al., 2012; Niemz et al., 2005; Widyanto \& Griffiths, 2011). In this sense, dissociation can be understood as a negative coping strategy of escape and avoidance, in which the player is reinforced by avoiding distress and daily hassles (Hagström \& Kaldo, 2013) and in which his or her role in the game may be more reinforcing than in real life (Fuster et al., 2012). Our results confirm previous studies where addictive online behavior was found to be associated with dissociative experiences (Musetti, Terrone, \& Schimmenti, 2018; Schimmenti \& Caretti, 2010; Schimmenti et al., 2012). However, it has still to be assessed to what degree the dissociation scale of the MMO-MS actually measures dissociation in the clinical sense; future studies on dissociative symptoms in addictive behaviors should also incorporate a standardized measure of dissociation, such as the Dissociative Experiences Scale (Carlson \& Putnam, 1993). 
Playing to escape from reality can be a healthy behavior, but when escaping turns into dissociation from reality, this dissociation together with a high immersion in the game contribute greatly to the development of addictive behaviors (Carbonell et al., 2009; Fuster et al., 2012).

Our linear regression model explains part of the variance, but it suggests that other factors that we have not considered may intervene. Undoubtedly, the complex relationships between life satisfaction, personality variables, and motivations for the game cannot be covered in a single study. This type of analysis forces the dependent variable to be the pathological game but, of course, this association is not causal. In addition, it is difficult to establish the meaning of this relationship. It may be that players with low self-esteem, with less satisfaction with life, and who need to escape from reality are likely to use the game with more intensity. Alternatively, it may be that family criticisms and the self-perception of highly involved or passionate players provoke lower self-esteem and life satisfaction.

In recent years, we have witnessed an increase in the number of proposed behavioral addictions, which are more or less well-founded, for example, addiction to studying (Atroszko, Andreassen, Griffiths, \& Pallesen, 2015), tanning (Nolan \& Feldman, 2009), aesthetic surgery (Suissa, 2008), talking (Bostrom \& Harrington, 1999; McCroskey \& Richmond, 1995), tango dancing (Targhetta, Nalpas, \& Perney, 2013), and reading Harry Potter books (Rudski, Segal, \& Kallen, 2009). Addiction to SWUG would be another example of these potentially pathological behaviors under consideration in research. It is certainly true that, with the exception of pathological gambling and IGD, behavioral addictions have been given little attention in the DSM and in the International Classification of Diseases of the World Health Organization; however, we might now be dealing with a kind of overpathologization of everyday life (Billieux, Schimmenti, Khazaal, Maurage, \& Heeren, 2015; Carbonell \& Panova, 2017; Frances \& Widiger, 2012; Mihordin, 2012).

To what extent can hobbies such as dancing tango, playing $X$-Wing, or using social networks online be addictions? Undoubtedly, some human activities are highly immersive, exciting, and fun, but these qualities are not necessarily to be identified with addiction. Addiction is a disorder in which a behavior that has no value for survival is repeated, which causes psychological dependence (and in the case of some drugs, also physical), and which has great potential to cause serious detrimental psychological, social, and/or physical effects (Sánchez-Carbonell, Beranuy, Castellana, Chamarro, \& Oberst, 2008; West, 2013). One important issue is that many of the possible behavioral addictions have been diagnosed using screening tests and surveys but almost never in a clinical setting (KardefeltWinther et al., 2017). Obviously, a characteristic of addiction is the sufferer's lack of awareness. Still, a positive test score cannot be a valid basis for diagnosing a patient or recognizing a new disease. Several people intensively immerse themselves in an activity during more or less prolonged periods without the negative consequences becoming severe enough to warrant a diagnosis. These activities can offer social and psychological rewards at a minimum personal cost, and practitioners can engage in them to seek pleasure and regulate their moods. On the contrary, more problematic uses are associated with loss of control, cognitive salience, and negative outcomes (Deleuze et al., 2015).

It might be more appropriate to consider them coping strategies, preparatory phases for becoming a professional or transitory passions. Kardefelt-Winther et al. (2017) highlights that we lack a theoretical framework that can guide research in this area, to the point where we risk pathologizing common behaviors. He instead insists that we should focus upon significant functional impairment and persistence over time.

The dualistic model of passion distinguishes between harmonious passion and obsessive passion (Lafrenière, Vallerand, Donahue, \& Lavigne, 2009; Vallerand et al., 2003). Both types of passion are positively associated with the experience of positive affect while playing and refer to the tendency to engage in an activity in which practitioners invest considerable time and energy. Harmonious passion involves an interest in engaging in some activity through their own volition that does not decline while engaged in the activity. Obsessive passion, on the other hand, refers to an uncontrollable urge forcing the individual to engage in the activity (Vallerand et al., 2003). The study of passion reveals that both forms of passion are commonly present in some immersive behaviors, and that while harmonious passion is positively related to wanting to play as well as game enjoyment, post-play energy, and self-realization; obsessive passion predicts the negative aspects associated with video gaming, such as the urge to play as well as the amount of time spent playing, states of post-game tension, and low levels of enjoyment of the game (Fuster, Chamarro, Carbonell, \& Vallerand, 2014).

This leads us again to the importance of knowing how to distinguish excessive (Kardefelt-Winther et al., 2017), passionate (Vallerand et al., 2003), and highly engaged behaviors (Charlton \& Danforth, 2007) from true behavioral addictions. In the case of SWUG, in addition, we find that players generally enjoy good self-esteem and are satisfied with their lives; the possible negative consequences of this hobby are minimal.

\section{LIMITATIONS OF THE STUDY}

The main shortcoming of this study is its small and self-selected sample of players. We contacted eligible participants through online forums (i.e., probably the most intensive SWUG players), and one third of the players registered on these forums responded to our request. Therefore, it is possible that the symptomatology of the general SWUG-playing population has been overestimated in this study, which makes the addictive potential of these games even less probable. Furthermore, although the IGD-20 has been validated for the Spanish-speaking population (Fuster et al., 2016), the short form we used in this study has not been validated; moreover, both scales have been designed for online gaming disorder and their applicability to board games also needs to be verified.

This study provides some future research paths, such as the comparative study of analog and virtual players. Table game players tend to be older than online gamers, and this fact can cause a certain stigma, because games dealing with 
fantasy universes have been related to childhood and adolescence. Finally, most research on video gaming suggests that game behavior is dependent on age, and that intensive gaming is most likely during young adulthood; these assumptions should be studied through empirical research.

\section{CONCLUSIONS}

Although SWUG can generate economic, personal, or family conflicts, and some players consider themselves to be "addicts," our research shows that the games are a safe hobby. Our analysis of SWUG calls into question the addictive potential of hobbies and challenges the acceptance of other possible behavioral addictions. This is an important moment of decision-making about behavioral addictions, in which the DSM-5 and the draft of the latest revision of the International Classification of Diseases (ICD-11) of the World Health Organization coincide in pointing out the need to study addiction to games in which material goods are not at stake and the intervention of chance is very limited. This study calls for caution in diagnosing behavioral addictions; we should refer to other explanatory models such as the passion model or high involvement in an activity. Nonetheless, we have observed that low selfesteem and low life satisfaction as well as playing to escape from reality are risks of suffering addictive symptoms. Therefore, it is advisable to continue studying behavioral addictions in order to reach a consensus among clinicians and researchers. On one hand, the goals should be to avoid pathologizing daily life, and on the other hand, to provide people with adequate diagnoses and treatments. Meanwhile, paraphrasing the famous phrase from the Star Wars films, we say to players: May the passion be with you!

Funding sources: This study was funded by the Spanish Ministry of Economy and Competitiveness (Ministerio de Economía y Competitividad, MINECO) with a grant for Research and Development (reference: FEM 2016-76136R). No competing financial interests exist.

Authors' contribution: FC designed the study, performed the data collection, and contributed to the drafting of the manuscript. XC supervised the design and procedure and worked out and wrote the main part of the manuscript. UO performed the data analysis, wrote "Results" section, and revised the manuscript. HF contributed to the statistical analysis and revision of the manuscript.

Conflict of interest: The authors declared no conflict of interest.

\section{REFERENCES}

American Psychiatric Association [APA]. (2013). Diagnostic and statistical manual of mental disorders (DSM-5). Arlington, VA: American Psychiatric Association.

Arrindell, W. A., Heesink, J., \& Feij, J. A. (1999). The Satisfaction With Life Scale (SWLS): Appraisal with 1700 health young adults in the Netherlands. Personality and Individual Differences, 26(5), 815-826. doi:10.1016/S0191-8869(98) 00180-9

Atienza, F., Pons, D., Balaguer, I., \& García-Merita, M. (2000). Propiedades psicométricas de la Escala de Satisfacción con la Vida en adolescentes [Psychometric properties of the Satisfaction with Life Scale in adolescents]. Psicothema, 12(1984), 314-319.

Atroszko, P. A., Andreassen, C. S., Griffiths, M. D., \& Pallesen, S. (2015). Study addiction - A new area of psychological study: Conceptualization, assessment, and preliminary empirical findings. Journal of Behavioral Addictions, 4(2), 75-84. doi:10.1556/2006.4.2015.007

Billieux, J., Schimmenti, A., Khazaal, Y., Maurage, P., \& Heeren, A. (2015). Are we overpathologizing everyday life? A tenable blueprint for behavioral addiction research. Journal of Behavioral Addictions, 4(3), 119-123. doi:10.1556/2006.4. 2015.009

Billieux, J., Van der Linden, M., Achab, S., Khazaal, Y., Paraskevopoulos, L., Zullino, D., \& Thorens, G. (2013). Why do you play World of Warcraft? An in-depth exploration of self-reported motivations to play online and in-game behaviours in the virtual world of Azeroth. Computers in Human Behavior, 29(1), 103-109. doi:10.1016/j.chb.2012.07.021

Bjorklund, D. F., \& Pellegrini, A. D. (2010). Evolutionary perspectives on social development. In P. K. Smith \& C. H. Hart (Eds.), The Wiley-Blackwell handbook of childhood social development (pp. 64-81). Oxford, UK: Wiley-Blackwell.

Bosch, R. A. (2000). Optimal card-collecting strategies for magic: The gathering. The College Mathematics Journal, 31(1), 15-21. doi:10.1080/07468342.2000.11974103

Bostrom, R. N., \& Harrington, N. G. (1999). An exploratory investigation of characteristics of compulsive talkers. Communication Education, 48(1), 73-80. doi:10.1080/0363 4529909379154

Cabañero, M. J., Richart, M., Cabrero, J., Orts, M. I., Reig, A., \& Tosal, B. (2004). Fiabilidad y validez de la Escala de Satisfacción con la Vida de Diener en una muestra de mujeres embarazadas y puérperas [Reliability and validity of Diener's Satisfaction with Life Scale in a sample of pregnant and puerperal women]. Psicothema, 16, 448-455.

Caplan, S. E., Williams, D., \& Yee, N. (2009). Problematic Internet use and psychosocial well-being among MMO players. Computers in Human Behavior, 25(6), 1312-1319. doi:10. 1016/j.chb.2009.06.006

Carbonell, X. (2014). La adicción a los videojuegos en el DSM-5 [Videogame addiction in the DSM-5]. Adicciones, 26(2), 9195. doi: 10.20882 /adicciones. 10

Carbonell, X. (2017). From Pong to Pokemon go, catching the essence of the Internet gaming disorder diagnosis: Commentary on: Chaos and confusion in DSM-5 diagnosis of Internet Gaming disorder: Issues, concerns, and recommendations for clarity in the field (Kuss et al.). Journal of Behavioral Addictions, 6(2), 124-127. doi:10.1556/2006.6.2017.010

Carbonell, X., Chamarro, A., Oberst, U., Rodrigo, B., \& Prades, M. (2018). Problematic use of the Internet and smartphones in university students: 2006-2017. International Journal of Environmental Research and Public Health, 15(3), 475. doi:10.3390/ijerph15030475

Carbonell, X., \& Panova, T. (2017). A critical consideration of social networking sites' addiction potential. Addiction 
Research \& Theory, 25(1), 48-57. doi:10.1080/16066359. 2016.1197915

Carbonell, X., Talarn, A., Beranuy, M., Oberst, U., \& Graner, C. (2009). Cuando jugar se convierte en un problema: el juego patológico y la adicción a los juegos de rol online [When gaming becomes a problem: Pathological gambling and addiction to online role-playing games]. Aloma, 25, 201-220.

Carlson, E. B., \& Putnam, F. W. (1993). An update on the Dissociative Experiences Scale. Dissociation: Progress in the Dissociative Disorders, 6(1), 16-27.

Charlton, J. P., \& Danforth, I. D. W. (2007). Distinguishing addiction and high engagement in the context of online game playing. Computers in Human Behavior, 23(3), 1531-1548. doi:10.1016/j.chb.2005.07.002

Crocker, J., Luhtanen, R., Blaine, B., \& Broadnax, S. (1994). Collective self-esteem and psychological well-being among white, black, and Asian college students. Personality and Social Psychology Bulletin, 20(5), 503-513. doi:10.1177/ 0146167294205007

Deleuze, J., Rochat, L., Romo, L., Van der Linden, M., Achab, S., Thorens, G., Khazaald, Y., Zullinod, D., Mauragea, P., Rothend, S., \& Billieux, J. (2015). Prevalence and characteristics of addictive behaviors in a community sample: A latent class analysis. Addictive Behaviors Reports, 1, 49-56. doi:10.1016/j.abrep.2015.04.001

Diener, E., Emmons, R., Larsen, J., \& Griffin, S. (1985). The Satisfaction With Life Scale. Journal of Personality Assessmemt, 49(1), 71-75. doi:10.1207/s15327752jpa4901_13

Frances, A. J., \& Widiger, T. (2012). Psychiatric diagnosis: Lessons from the DSM-IV past and cautions for the DSM-5 future. Annual Review of Clinical Psychology, 8(1), 109-130. doi:10.1146/annurev-clinpsy-032511-143102

Fuster, H., Carbonell, X., Chamarro, A., \& Oberst, U. (2013). Interaction with the game and motivation among players of massively multiplayer online role-playing games. The Spanish Journal of Psychology, 16, 1-8. doi:10.1017/sjp.2013.54

Fuster, H., Carbonell, X., Pontes, H. M., \& Griffiths, M. D. (2016). Spanish validation of the Internet Gaming Disorder-20 (IGD20) Test. Computers in Human Behavior, 56, 215-224. doi:10.1016/j.chb.2015.11.050

Fuster, H., Chamarro, A., Carbonell, X., \& Vallerand, R. J. (2014). Relationship between passion and motivation for gaming in players of massively multiplayer online role-playing games. Cyberpsychology, Behavior and Social Networking, 17(5), 292-297. doi:10.1089/cyber.2013.0349

Fuster, H., Oberst, U., Griffiths, M. D., Carbonell, X., Chamarro, A., \& Talarn, A. (2012). Psychological motivation in online role-playing games: A study of Spanish World of Warcraft players. Anales de Psicología, 28(1), 274-280.

Greger, H. K., Myhre, A. K., Klöckner, C. A., \& Jozefiak, T. (2017). Childhood maltreatment, psychopathology and wellbeing: The mediator role of global self-esteem, attachment difficulties and substance use. Child Abuse \& Neglect, 70, 122-133. doi:10.1016/j.chiabu.2017.06.012

Griffiths, M. D. (2010). The role of context in online gaming excess and addiction: Some case study evidence. International Journal of Mental Health and Addiction, 8(1), 119-125. doi:10.1007/s11469-009-9229-x

Hagström, D., \& Kaldo, V. (2013). Escapism among players of MMORPGs. Conceptual clarification, its relation to mental health factors, and development of a new measure.
Cyberpsychology, Behavior and Social Networking, 17(1), 19-25. doi:10.1089/cyber.2012.0222

Hussain, Z., \& Griffiths, M. D. (2009). The attitudes, feelings, and experiences of online gamers: A qualitative analysis. CyberPsychology \& Behavior, 12(6), 747-753. doi:10.1089/cpb. 2009.0059

Kaczmarek, L. D., \& Drążkowski, D. (2014). MMORPG escapism predicts decreased well-being: Examination of gaming time, game realism beliefs, and online social support for offline problems. Cyberpsychology, Behavior and Social Networking, 17(5), 298-302. doi:10.1089/cyber.2013.0595

Kahn, A. S., Shen, C., Lu, L., Ratan, R. A., Coary, S., Hou, J., Meng, J., Osborn, J., \& Williams, D. (2015). The Trojan Player typology: A cross-genre, cross-cultural, behaviorally validated scale of video game play motivations. Computers in Human Behavior, 49, 354-361. doi:10.1016/j.chb.2015.03.018

Kardefelt-Winther, D. (2014). The moderating role of psychosocial well-being on the relationship between escapism and excessive online gaming. Computers in Human Behavior, 38, 68-74. doi:10.1016/j.chb.2014.05.020

Kardefelt-Winther, D., Heeren, A., Schimmenti, A., van Rooij, A., Maurage, P., Carras, M., Edman, J., Blaszczynski, A., Khazaal, Y., \& Billieux, J. (2017). How can we conceptualize behavioural addiction without pathologizing common behaviours? Addiction, 112(10), 1709-1715. doi:10.1111/add.13763

Khantzian, J. (1985). The self-medication hypothesis of addictive disorders: Focus on heroin and cocaine dependence. American Journal of Psychiatry, 142(11), 1259-1264. doi:10.1176/ajp. 142.11.1259

King, D. L., \& Delfabbro, P. H. (2014). The cognitive psychology of Internet gaming disorder. Clinical Psychology Review, 34(4), 298-308. doi:10.1016/j.cpr.2014.03.006

Kuss, D. J., Griffiths, M. D., \& Pontes, H. M. (2016). Chaos and confusion in DSM-5 diagnosis of Internet gaming disorder: Issues, concerns, and recommendations for clarity in the field. Journal of Behavioral Addictions, 6(2), 103-109. doi:10.1556/ 2006.5.2016.062

Lafrenière, M.-A., Vallerand, R. J., Donahue, E. G., \& Lavigne, G. L. (2009). On the costs and benefits of gaming: The role of passion. CyberPsychology \& Behavior, 12(3), 285-290. doi:10.1089/cpb.2008.0234

Leung, L. (2007). Leisure boredom, sensation seeking, self-esteem, addiction: Symptoms and patterns of mobile phone use. In E. A. Konijn, S. Utz, M. Tanis, \& S. B. Barnes (Eds.), Mediated interpersonal communication (pp. 359-381). New York, NY: Routledge.

Loinaz, I., Echeburúa, E., \& Ullate, M. (2012). Estilo de apego, empatía y autoestima en agresores de pareja [Attachment style, empathy and self-esteem in partner-violent men]. Terapia Psicologica, 30(2), 61-70. doi:10.4067/S0718-48082012000 200006

Manganiello, J. A. (1978). Opiate addiction: A study identifying three systematically related psychological correlates. International Journal of the Addictions, 13(5), 839-847. doi:10.3109/ 10826087809039307

Martin, T. (2017). How board games became a billion-dollar business. New Statesman. Retrieved from https://www. newstatesman.com/culture/games/2017/01/how-board-gamesbecame-billion-dollar-business

Martín-Albo, J., Núñez, J. L., Navarro, J. G., \& Grijalvo, F. (2007). The Rosenberg Self-Esteem Scale: Translation and validation 
in university students. The Spanish Journal of Psychology, 10(2), 458-467. doi:10.1017/S1138741600006727

Maslow, A. (1954). Motivation and personality. New York, NY: Harper \& Row.

McCroskey, J. C., \& Richmond, V. P. (1995). Correlates of compulsive communication: Quantitative and qualitative characteristics. Communication Quarterly, 43(1), 39-52. doi:10. 1080/01463379509369954

Mihordin, R. (2012). Behavioral addiction - Quo Vadis? The Journal of Nervous and Mental Disease, 200(6), 489-491. doi:10.1097/NMD.0b013e318257c503

Musetti, A., Terrone, G., \& Schimmenti, A. (2018). An exploratory study on problematic Internet use predictors: Which role for attachment and dissociation? Clinical Neuropsychiatry, 15(1), $35-41$

Niemz, K., Griffiths, M. D., \& Banyard, P. (2005). Prevalence of pathological Internet use among university students and correlations with self-esteem, the general health questionnaire (GHQ), and disinhibition. CyberPsychology \& Behavior, 8(6), 562-570. doi:10.1089/cpb.2005.8.562

Nolan, B. V., \& Feldman, S. R. (2009). Ultraviolet tanning addiction. Dermatologic Clinics, 27(2), 109-112. doi:10. 1016/j.det.2008.11.007

Pontes, H. M., \& Griffiths, M. D. (2015). Measuring DSM-5 Internet gaming disorder: Development and validation of a Short Psychometric Scale. Computers in Human Behavior, 45, 137-143. doi:10.1016/j.chb.2014.12.006

Pontes, H. M., Szabo, A., \& Griffiths, M. D. (2015). The impact of Internet-based specific activities on the perceptions of Internet addiction, quality of life, and excessive usage: A crosssectional study. Addictive Behaviors Reports, 1, 19-25. doi:10.1016/j.abrep.2015.03.002

Rosenberg, M. (1965). Society and the adolescent self-image. Princeton, NJ: Princeton University Press.

Rudski, J. M., Segal, C., \& Kallen, E. (2009). Harry Potter and the end of the road: Parallels with addiction. Addiction Research \& Theory, 17(3), 260-277. doi:10.1080/16066350802334595

Sánchez-Carbonell, X., Beranuy, M., Castellana, M., Chamarro, A., \& Oberst, U. (2008). La adiccion a Internet y al móvil: ¿Moda o trastorno? [Internet and mobile phone addiction: Fashion or disorder?] Adicciones, 20(2), 149-160. doi:10.20882/adicciones. 279

Schick, L. (1991). Heroic worlds: A history and guide to role-playing games. Westminster, MD: Prometheus.
Schimmenti, A., \& Caretti, V. (2010). Psychic retreats or psychic pits?: Unbearable states of mind and technological addiction. Psychoanalytic Psychology, 27(2), 115-132. doi:10.1037/ a0019414

Schimmenti, A., \& Caretti, V. (2016). Linking the overwhelming with the unbearable: Developmental trauma, dissociation, and the disconnected self. Psychoanalytic Psychology, 33(1), 106-128. doi:10.1037/a0038019

Schimmenti, A., Guglielmucci, F., Barbasio, C., \& Granieri, A. (2012). Attachment disorganization and dissociation in virtual worlds: A study on problematic Internet use among players of online role playing games. Clinical Neuropsychiatry, 9(5), 195-202.

Sperber, A. D. (2004). Translation and validation of study instruments for cross-cultural research. Gastroenterology, 126 , S124-S128. doi:10.1053/j.gastro.2003.10.016

Suissa, A. J. (2008). Addiction to cosmetic surgery: Representations and medicalization of the body. International Journal of Mental Health and Addiction, 6(4), 619-630. doi:10.1007/ s11469-008-9164-2

Tabachnick, B. G., \& Fidell, L. S. (2007). Using multivariate statistics. Boston, MA: Allyn \& Bacon/Pearson Education.

Targhetta, R., Nalpas, B., \& Perney, P. (2013). Argentine tango: Another behavioral addiction? Journal of Behavioral Addictions, 2(3), 179-186. doi:10.1556/JBA.2.2013.007

Vallerand, R. J., Blanchard, C., Mageau, G. A., Koestner, R., Ratelle, C., Leonard, M., Gagne, M., \& Marsolais, J. (2003). Les passions de l'âme: On obsessive and harmonious passion. Journal of Personality and Social Psychology, 85(4), 756-767. doi:10.1037/0022-3514.85.4.756

West, R. (2013). Models of addiction (No. 14). European Communities. Retrieved from http://www.emcdda.europa.eu/ attachements.cfm/att_213861_EN_TDXD13014ENN.pdf

Widyanto, L., \& Griffiths, M. D. (2011). An empirical study of problematic Internet use and self-esteem. International Journal of Cyber Behavior, Psychology and Learning, 1(1), 13-24. doi:10.4018/ijcbpl.2011010102

Wood, R. T. A., Griffiths, M. D., \& Parke, A. (2007). Experiences of time loss among videogame players: An empirical study. CyberPsychology \& Behavior, 10(1), 38-44. doi:10.1089/ cpb.2006.9994

Yee, N. (2006). Motivations for play in online games. CyberPsychology \& Behavior, 9(6), 772-775. doi:10.1089/cpb.2006. 9.772 